\title{
GABAergic circuit dysfunctions in neurodevelopmental disorders
}

\section{Bidisha Chattopadhyaya and Graziella Di Cristo*}

CHU Sainte-Justine, Centre de Recherche, Université de Montréal, Montreal, QC, Canada

Edited by:

Daniela Tropea, Trinity College Dublin Ireland

\section{Reviewed by:}

Fabrice Ango, University of

Montpellier, France

Tommaso Pizzorusso, Istituto di

Neuroscienze Consiglio Nazionale

delle Ricerche, Italy

${ }^{*}$ Correspondence:

Graziella Di Cristo, CHU

Sainte-Justine, Centre de Recherche, Université de Montréal, 3175

Côte-Sainte-Catherine, Montreal, QC,

Canada.

e-mail: graziella.dicristo@

recherche-ste-justine.qc.ca
GABAergic interneurons control neuronal excitability, integration, and plasticity. Further, they regulate the generation of temporal synchrony and oscillatory behavior among networks of pyramidal neurons. Such oscillations within and across neural systems are believed to serve various complex functions, such as perception, movement initiation, and memory. Alterations in the development of GABAergic circuits have been implicated in various brain diseases with neurodevelopmental origin. Here, we highlight recent studies suggesting a role for alterations of GABA transmission in the pathophysiology of two neurodevelopmental diseases, schizophrenia, and autism. We further discuss how manipulations of GABA signaling may be used for novel therapeutic interventions.

Keywords: GABA, autism, schizophrenia, neurodevelopmental plasticity, basket cells, interneurons, development
Cortical neural networks consist of broadly two classes of neurons: excitatory projection neurons, primarily using glutamate as neurotransmitter, and inhibitory local-circuit interneurons, comprising of about $20 \%$ of all cortical neurons, and primarily using gamma-amino butyric acid (GABA) as a neurotransmitter. The last few years have seen a steep increase in our knowledge of the function of GABAergic interneurons. Cortical interneurons have been shown to play a vital role in modulating neuronal excitability (Swadlow, 2003), integration (Pouille and Scanziani, 2001), and in the generation of temporal synchrony and oscillation among networks of glutamatergic neurons (Klausberger and Somogyi, 2008). In addition, GABAergic interneurons contribute to almost all fundamental processes of cortical development; from neuronal proliferation, migration, and differentiation to experience-dependent refinement of local cortical circuits (Owens and Kriegstein, 2002; Hensch, 2005; Sernagor et al., 2010).

These findings have prompted a change in the way we view the role of GABAergic cells in cortical development and processing. Traditionally, GABAergic interneuron function has been described simply as "inhibition" of neuronal activity, similar to a traffic officer who signals simply to let cars stop or go; however it is now clear that the picture is much more complex. We may instead compare GABAergic interneuron function to that of a conductor of a symphony orchestra, whose role is to structure and coordinate the overall musical performance and interpretation of the individual players. Without proper direction, the orchestra cannot produce the right melody.

Considering the multifaceted role played by GABAergic cells in the development, function, and plasticity of cortical networks, it is straightforward to assume that any disturbance in the development of GABAergic interneurons, due to either genetic or epigenetic factors, will strongly affect brain function. Indeed, disruption of GABAergic circuit function has been implicated in various neurodevelopmental and psychiatric disorders including schizophrenia (Gonzalez-Burgos et al., 2011), autism (LeBlanc and Fagiolini, 2011), mental retardation (Cramer et al., 2010), and epilepsy (Rossignol, 2011). Our understanding of the mechanisms underlying development of GABAergic interneurons have started to reveal specific molecular and cellular substrates potentially affected in neurodevelopmental disorders. Further, selective modulation of inhibitory networks is being currently investigated as a tool to re-introduce plasticity and therefore facilitate the restoration of normal function to the diseased brain.

This review will summarize some of the compelling evidence on the role of alterations in GABAergic neuron function in the etiology of two neurodevelopmental disorders, schizophrenia, and autism. An exhaustive review of the genetic causes of schizophrenia and autism is beyond the scope of this paper, and several excellent reviews have already been published on these topics. We will further focus on and discuss recent efforts to modify GABAergic transmission as a targeted therapeutic approach to re-introduce plasticity in the brain.

\section{CORTICAL INTERNEURON DIVERSITY - A CONTINUOUS CHALLENGE}

Before describing evidence linking GABAergic dysfunction to neurodevelopmental diseases, we would like to stress that our understanding of GABAergic interneuron function in normal and pathological conditions is challenged by their startling heterogeneity. Indeed different interneuron subtypes display distinctly different morphology, physiological properties, connectivity patterns, and vary in their biochemical composition (Markram et al., 2004). Such complexity makes it difficult to establish a broad consensus regarding a generalized classification scheme of 
interneuron subtypes. In parallel however, several studies have singled out multiple criteria to distinguish between major interneuron groups. One criterion for instance is the expression of calcium binding proteins such as parvalbumin (PV), calbindin (CB), or calretinin (CR) and/or neuropeptides such as somatostatin (SST), vasoactive intestinal peptide (VIP), neuropeptide Y (NPY), or cholecystokinin (CCK). Such analysis has shown that the cortex has three largely independent populations of interneurons: (1) PV, (2) SST/CB, and (3) CR/VIP expressing interneurons (Somogyi et al., 1998).

Further, different subtypes of interneurons have different spatial and temporal origins. The neocortical interneuron population, as such, is derived from transient ventral telencephalic structures referred to as the ganglionic eminences as well as from the preoptic area (Batista-Brito and Fishell, 2009; Gelman and Marín, 2010). The medial ganglionic eminence (MGE) produces $\sim 70 \%$ of neocortical interneurons, including the PV-expressing and SST-positive interneurons. Meanwhile, the caudal ganglionic eminence (CGE) gives rise to a more heterogeneous group of cortical interneurons that share the expression of 5HT3A ionotropic serotoninergic receptors and are thus highly responsive to the neuromodulatory effects of serotonin (Batista-Brito and Fishell, 2009; Gelman and Marín, 2010; Lee et al., 2010).

Another striking characteristic of GABAergic interneurons is that different subtypes innervate distinct domains of the postsynaptic glutamatergic cells. For example, SST/CB expressing interneurons selectively innervate distal dendrites of target neurons, while PV-expressing, fast-spiking interneurons can be divided in two major classes, basket cells which selectively innervate the soma and proximal dendrites and chandelier cells, which selectively innervate the axon initial segment of pyramidal cells (Huang et al., 2007). The spatial organization of GABAergic synapses along glutamatergic neurons has provided important clues as to the specific functions of various interneuron subtypes (Huang et al., 2007; Rossignol, 2011).

To truly understand how GABAergic circuits develop and function, it is essential to differentiate between distinct GABAergic interneuron subtypes. It is indeed likely that specific interneuron types differentially contribute to network processing that underlies cortical functions ranging from perception to cognition. Consequently, we can hypothesize that deficits in specific interneuron classes may account, at least in part, for different neuropathological conditions.

Recent technical advances have significantly accelerated progress in the interneuron field. In particular, the development of genetic strategies based on interneuron cell type-specific promoters in combination with inducible Cre-loxP knockin driver lines and fluorescent protein reporter lines has allowed efficient high-resolution labeling and manipulation of specific GABAergic interneuron classes in intact or "semi-intact" tissues (such as organotypic brain cultures; Chattopadhyaya et al., 2004, 2007; Taniguchi et al., 2011). Due to the availability of these new tools, it is now possible to study specific GABAergic interneuron types, from cell fate specification, migration, and connectivity, to their function in network dynamics and behavior. Combining insights obtained from basic biological research on GABAergic interneuron development, plasticity, and function with genetic and clinical findings will provide us a detailed picture of the molecular events that result in diseases characterized by GABAergic dysfunction, and will suggest putative useful methods for targeted corrective intervention.

\section{GABAergic ALTERATIONS IN NEURODEVELOPMENTAL DISEASES}

\section{SCHIZOPHRENIA}

Schizophrenia is a severe brain disorder that afflicts $0.5-1 \%$ of the world's population and is usually first diagnosed in late adolescence or early adulthood. The illness manifests with three classes of symptoms: positive or psychotic symptoms (i.e., delusions, hallucinations, and disorganization of thought), negative symptoms (i.e., flat affect, avolition, and alogia), and cognitive impairments such as abnormalities in working memory, inferential thinking, selective attention, as well as defects in executive functions, linguistic fluency, and social-emotional processing.

Although positive symptoms presents the most prominent clinical feature of schizophrenia, disturbances in cognition appear to be the core feature of the illness as they are present before the onset of psychosis and are the best predictor of long-term functional outcome for schizophrenia patients. Therefore, understanding neural mechanisms underlying cognitive and dysfunctions is critical to develop new therapeutic strategies particularly given that currently approved pharmacological treatments for schizophrenia are largely ineffective at improving cognition.

A central cognitive deficit in schizophrenia is the dysfunction of working memory, i.e., the ability to store information and use it while performing complex tasks (Baddeley, 2010). Gamma oscillations $(30-80 \mathrm{~Hz})$ are thought to play an important role in normal working memory because gamma band synchrony increases with increasing working memory load (Howard et al., 2003). In patients with schizophrenia, working memory deficits are accompanied by altered patterns of cortical oscillatory activity. In particular, gamma activity does not augment with increasing working memory load in schizophrenia patients (Basar-Eroglu et al., 2007; Barr et al., 2010; Haenschel and Linden, 2011). Working memory related gamma activity, but not theta activity, is reduced in the frontal cortex of first-episode schizophrenia patients independent of medication status, suggesting a deficit related to the disease process as opposed to medication side effects or as a consequence of being chronically ill (Minzenberg et al., 2010). Moreover, subjects with schizophrenia have decreased oscillations in various frequency bands during specific phases of the working memory process including encoding, maintenance, and retrieval (Haenschel et al., 2009).

Among the several mechanisms proposed to play a role in the generation of synchronized oscillations in neocortical circuits, computational modeling studies, and numerous experimental evidence support a leading role of GABA-mediated inhibition. In particular, convergent evidence indicates that synchronous activity in $\mathrm{PV}$-expressing, fast-spiking basket interneurons is key to the emergence of gamma oscillations (Bartos et al., 2007). In vitro studies in rodent hippocampus and cortex show that blocking GABA suppresses gamma oscillations, and that driving fast-spiking interneurons by activating metabotropic glutamate receptors generates gamma oscillations (Whittington et al., 1995; Bartos et al., 2002). 
Correlative in vivo studies similarly show that fast-spiking cells fire action potentials in phase with the gamma oscillations in the neocortex (Hasenstaub et al., 2005; Sirota et al., 2008). Causal evidence for this hypothesis in vivo has been recorded in the neocortex using optogenetics, which allow the bidirectional modulation of neuronal activity of selective cell populations that have been made sensitive to light by genetic manipulation. Optogenetic-mediated activation of PV-expressing interneurons selectively amplifies gamma oscillations and modulates sensory responses in rat somatosensory cortex (Cardin et al., 2009). Conversely, suppressing PVexpressing interneuron activity with optogenetic methods significantly reduced or abolished gamma oscillations (Sohal et al., 2009). Finally, mice lacking NMDAR-mediated neurotransmission only in PV-expressing interneurons show altered cortical gamma rhythms with largely normal behavior except for selective cognitive impairments, including deficits in habituation, working memory, and associative learning (Carlén et al., 2011). Therefore, GABA $\mathrm{R}$ mediated currents from PV-expressing basket cells appear to be the main source of GABA-mediated synchronization underlying cortical gamma oscillations.

In parallel, evidence from post-mortem studies of brains of subjects with schizophrenia supports the notion that specific alterations in GABAergic interneurons are associated with this disease (Lewis et al., 2005). In particular, one of the most reliable findings in schizophrenia research is the decrease in mRNA for GABA-synthesizing enzyme GAD67, which appears to be markedly deficient in PV-positive interneurons in schizophrenic brains (Hashimoto et al., 2003; Lewis et al., 2005). In addition, several GABA-related transcripts including those for GAD67, PV, the GABA transporter GAT1, SST, and the GABA $\mathrm{R}$ subunits $\alpha 1$ and $\delta$, are decreased in dorsolateral PFC as well as in the anterior cingulate, primary motor, and primary visual cortices (Hashimoto et al., 2008). Overall these data suggest that disturbances in GABAergic neurotransmission in specific cell types could represent a common pathological mechanism for different domains of cortical dysfunction in schizophrenia. It is therefore possible that pharmacological agents with the appropriate specificity for certain GABAergic synapses might be effective for a range of clinical features in the illness. While direct demonstration of a decrease in GABA-mediated synaptic transmission, in particular from basket cells, in the cortex of subjects with schizophrenia is challenging and still missing, the evidence available at the moment strongly points toward a direct link between PV-positive basket cell dysfunction, gamma oscillation alterations, and working memory deficits in schizophrenia patients.

Understanding PV-positive basket cell development in normal conditions should indicate the natural events occurring during this process and point out potential pathogenic mechanisms that can cause GABAergic dysfunction and schizophrenia. GABAergic interneuron development is a prolonged process, which starts in the embryo, progresses through childhood, and is completed by adolescence in all mammalian species studied including rodents and humans. During this prolonged period, the interplay between genetic, epigenetic, and environmental factors can produce subtle developmental alterations in GABAergic circuits that may contribute to the pathophysiology of schizophrenia.
While the molecular mechanisms regulating postnatal development of basket cells are not yet fully understood, recent papers have started to address this issue. In particular, it has been shown that the maturation of perisomatic innervation from GABAergic basket cells is modulated by neuronal activity and sensory experience during a critical postnatal period (Chattopadhyaya et al., 2004; Chattopadhyaya, 2011). A crucial factor regulating the development of innervation patterns by basket cells is GABA release itself, which regulates both the number of postsynaptic targets, as well as the number of synapses made onto each target by a single basket cell, in an age-dependent manner (Chattopadhyaya et al., 2007; Baho and Di Cristo, 2012; Wu et al., 2012). In particular, GAD67 knockdown in single basket cells dramatically decreases the formation of terminal axon branches and perisomatic synapses, as well as the number of postsynaptic neurons innervated by each basket cell (Chattopadhyaya et al., 2007). This finding is particularly interesting since polymorphisms in the $5^{\prime}$ region of the Gadl gene (coding for GAD67) have been associated with decreased GAD67 and schizophrenia (Addington et al., 2005; Straub et al., 2007). One possibility, therefore, is that altered inhibitory transmission caused by the genetic impairment of GAD67 gene early in development might alter the developmental trajectory of GABAergic neural circuit maturation, thus causing global network alterations predisposing to schizophrenia.

Another remarkable study showed that the trophic factor Neuregulin-1 and its receptor ErbB4, which are both schizophrenia susceptibility genes, regulate the development of PVpositive basket cell synapses (Fazzari et al., 2010). Further, Neuregulin signaling facilitates activity-dependent GABA release from mature basket cells and selective loss of ErbB4 in these cells causes a disinhibition of prefrontal pyramidal cells and results in schizophrenia-relevant phenotypes in mice (Wen et al., 2010).

In another study, the polysialylated form of the neural cell adhesion molecule NCAM has been shown to regulate the timing of perisomatic GABAergic synapse maturation in mouse cortex (Di Cristo et al., 2007). NCAM is polysialylated by two polysialyltransferases ST8SiaII and ST8SiaIV. SNPs in ST8SIaII have been implicated in schizophrenia (Arai et al., 2006; Tao et al., 2007; Isomura et al., 2011), providing a mechanism by which genetic interference with the complex coordination of NCAM polysialylation and GABAergic synapse maturation may lead to a neurodevelopmental predisposition to psychiatric disease.

In summary, multiple lines of evidence both in humans and animals suggests that the development and function of PVexpressing interneuron are particularly affected in schizophrenia. How can we use this knowledge to design novel targeted therapeutic approaches? Understanding the mechanisms underlying PV-expressing basket cell synapse development and plasticity may give us tools to modulate their function. Further, it has been proposed that combining pharmacological tools to enhance neural synchrony mediated by PV-positive basket cells along with behavioral therapies involving learning paradigms to reduce or reverse the consequences of altered neuronal circuit development could be an effective means of improving cognitive control in individuals with schizophrenia (Gonzalez-Burgos et al., 2011; Lewis, 2011). It is however important to underline that basket neurons are not the only ones affected in schizophrenia and future efforts are 
needed to understand how alterations in specific circuits give rise to associated cognitive impairments.

\section{AUTISM}

Autism is a complex neurodevelopmental disorder characterized by abnormal socialization, deficits in verbal and non-verbal communication, and a limited interest in the surrounding environment associated with stereotyped and repetitive behaviors. The incidence of this disorder, which varies between 10 and 20 per 10000 children, has risen dramatically over the past two decades mainly because of the use of broader diagnostic criteria and the increased attention of the medical community (Levy et al., 2009). Clinical signs are usually present at the age of 3 years, but prospective studies of infants at risk have demonstrated that deficits in social responsiveness and communication could already be present as early as 6-12 months.

A high concordance rate between monozygotic twins ( $70 \%)$ and a significant sibling risk suggests that autism has a strong genetic component (Bailey et al., 1995). Although there is a clear genetic basis to autism, the majority of cases have unknown causes (non-syndromic autism). Similar to other complex brain diseases, it is likely that inherited risk factors, in combination with certain environmental or epigenetic triggers, ultimately causes autism. For many human diseases, the generation and characterization of animal models is an essential bridge between understanding the biological features of the disease and the development of targeted therapeutic approaches. The high genetic inheritance of autism has resulted in the generation of several animal models, however their validation has been controversial. Indeed, in the case of autism, modeling human symptoms requires rigorous behavioral tests to examine socialization, communication, and repetitive behavior, which are rather difficult to do in mice.

The majority of autism research has focused on the higher cognitive symptoms, however, its important to consider that the development and proper execution of higher cognitive processes depends on basic primary processing. The behaviors typically altered in autism arise from multiple sensory areas; for example, communication and socialization involve parallel auditory, visual, and somatosensory information processing. Recent studies suggest that altered low-level perceptual information processing is one of the main problems in autism, and this affects higher integrative areas of the brain (Bertone et al., 2003; Belmonte et al., 2004). Systematic developmental studies in autistic, high-risk infant siblings and control subjects are necessary to better understand the role of sensory processing and perception in the pathogenesis of autism. Nevertheless, these studies suggest that testing sensory processing in mouse models of autism is a promising approach that could allow for a better understanding of the biological features altered in the autistic brain.

Studies in autistic patients strongly suggest a correlation with dysfunction in the GABAergic system. For example, analysis of post-mortem tissues from autistic patients has shown that the GABA-synthesizing enzymes GAD65 and GAD67 are significantly reduced $(\sim 50 \%)$ in the parietal cortex and cerebellum (Fatemi et al., 2002; Yip et al., 2007). Multiple studies have also found both $\mathrm{GABA}_{\mathrm{A}}$ and $\mathrm{GABA}_{\mathrm{B}}$ receptor alterations in autistic brains (Collins et al., 2006; Fatemi et al., 2009, 2010; Oblak et al., 2010). Reduced benzodiazepine binding to hippocampal $\mathrm{GABA}_{\mathrm{A}}$ receptors further suggests altered modulation of $\mathrm{GABA}_{\mathrm{A}}$ receptors in the presence of GABA (Guptill et al., 2007). The cortex is organized in vertical mini columns of functionally related glutamatergic and GABAergic neurons that process thalamic inputs. Local GABAergic circuits contribute to control the functional integrity of minicolumns via lateral inhibition. Interestingly, the number of mini columns is increased while their width is decreased in autistic brains indicating abnormal cortical organization regulated by inhibitory circuitry (Casanova et al., 2003). Further, a meta-analysis study of PV expression across multiple autism mouse models found a consistent reduction of PV-positive cells in the neocortex of autism mouse models as compared to controls (Gogolla et al., 2009). Maybe one of the most convincing indications of altered GABAergic function in autism is the high co-morbidity of autism with epilepsy. Altered GABA function may reduce the threshold for developing seizures. Indeed, $\sim 30 \%$ of autistic patients also have epilepsy, and inter-ictal epileptic activity recorded on scalp EEG occurs in up to $85 \%$ of autistic children (Gillberg and Billstedt, 2000; Yasuhara, 2010).

Non-idiopathic autism has been difficult to study because of the lack of suitable animal models. By comparing the molecular mechanisms underlying different single-gene disorders, it may be possible to discover commonalities and general principles that might hold true even for those cases in which no specific genetic cause has been identified. Dysfunction of GABAergic signaling has been shown to occur in the majority of animal models of autism obtained by experimentally manipulating candidate genes for autism susceptibility. Here, we summarize the GABAergic dysfunctions found in animal models carrying either rare mutations identified in autism patients or mutations known to cause diseases that are comorbid with autism. In fact, autism is comorbid with a number of other diseases, including Rett and Angelman Syndrome, which have known genetic causes and have been modeled in transgenic mice.

\section{Mutations in neuroligin-neurexin adhesion complex}

A small percentage of autistic patients carry single mutations in genes encoding for synaptic cell adhesion molecules of the neurexin (NRXN)-neuroligin (NLG) families. These include mutations in genes encoding for NRXN1 (Szatmari et al., 2007; Kim et al., 2008), NLG3, and NLG4 (Jamain et al., 2003; Laumonnier et al., 2004). Neuroligins are postsynaptic transmembrane molecules localized at both excitatory and inhibitory synapses, where they bind with presynaptic neurexins. Neuroligin-neurexin complex has been shown to regulate the formation of both excitatory and inhibitory synapse (for a review see Craig and Kang, 2007; Huang and Scheiffele, 2008; Südhof, 2008). In particular, a point mutation (R451C) that replaces an arginine with a cysteine in the extracellular portion of neuroligin-3 was identified in two brothers, one with severe autism and the other with Asperger syndrome (Jamain et al., 2003). In addition, a mutation in neuroligin- 4 has been discovered in another set of autistic brothers (Jamain et al., 2003). Interestingly, mice carrying the mutation R451C show an upregulation of inhibitory markers, including the vesicular GABA transporter (VGAT) and the postsynaptic scaffolding protein gephyrin. Further, inhibitory transmission in 
the somatosensory cortex is functionally augmented as shown by increased frequency of miniature IPSCs, increased amplitude of evoked IPSCs, and increased IPSC amplitude in response to GABA application. Mutant mice show behaviors relevant to autism, including altered socialization and enhanced spatial learning (Tabuchi et al., 2007; but see also Chadman et al., 2008). However, none of these molecular, physiological, and behavioral phenotypes were found in neuroligin-3 knockout mice, suggesting that this particular mutation results in a gain-of-function though the mechanism is still not well understood. In addition, mice lacking neuroligin-4 show lack of reciprocal social interaction and reduced ultrasonic vocalization, providing further evidence that mutant neuroligin mouse models may be useful to study neuronal circuit alterations in autism (Jamain et al., 2008).

\section{Rett syndrome}

Mutations in the X-linked MeCP2 gene, which encodes the transcriptional regulator methyl-CpG-binding protein 2 (MeCP2), causes the majority of Rett syndrome the majority of Rett syndrome cases. Rett syndrome is characterized by an apparently normal early development followed by developmental regression, including loss of language skills, motor abnormalities, cognitive deficits, stereotyped behavior, respiratory dysrhythmias, and seizures sometimes leading to premature death.

To uncover the molecular changes that underlie Rett syndrome, mouse models with different MeCP2 mutations have been generated. The analysis of synaptic circuit structure and function in these mouse lines showed several defects in the formation/maturation of neuronal GABAergic connectivity, which seem to be specific to selected brain regions, including the ventro-lateral medulla, the ventral basal complex, the reticular thalamic nucleus, and the cerebellum (reviewed in Boggio et al., 2010). Interestingly, wildtype GABAergic neurons express 50\% more MeCP2 than wildtype non-GABAergic cells. Based on this observation, a conditional mutant mouse was generated where MeCP2 was exclusively disrupted in GABAergic cells using a VGAT-Cre mouse line. These mice develop nearly all of the symptoms that arise in germline $\mathrm{MeCP} 2$ knockout mice, including limb clasping, selfinjury from excessive grooming, motor deficiencies, increased prepulse inhibition, altered socialization, and decreased lifespan. Further, GABAergic neurons, in these mice, exhibit reduced inhibitory quantal size, reduced GAD65 and GAD67 levels, and reduced GABA immunoreactivity. In addition, specific knockout of MeCP2 in forebrain GABAergic neurons recapitulates many of the symptoms observed in germline MeCP2 knockout mice (Chao et al., 2010), therefore suggesting that disruption of MeCP2 exclusively in inhibitory neurons is sufficient to cause Rett syndrome in mice.

\section{Angelman syndrome}

Linkage and association studies have revealed that the chromosomal region 15q11-q13 is strongly implicated in autism spectrum disorders (Shao et al., 2003). Maternal duplications of this region remains one of the most common cytogenetic abnormalities found in cases of idiopathic autism, which account for $1-2 \%$ of the total cases. Deletion of this region results in either Angelman or PraderWilli syndrome, depending on which parent the deletion comes from. Within this chromosomal region, there is a gene cluster of $\mathrm{GABA}_{\mathrm{A}}$ receptors: Gabrb3, Gabra5, and Gabrg3, encoding for $\beta 3, \alpha 5$, and $\gamma 3$ subunits, respectively. Individuals with 15q11-13 deletions usually have more severe epilepsy than those with more specific mutations for example in the gene E3 ubiquitin ligase, which are sufficient to cause Angelman syndrome, but spares the $\mathrm{GABA}_{\mathrm{A}} \mathrm{R}$ gene clusters (Minassian et al., 1998). Among different $\mathrm{GABA}_{\mathrm{A}}$ receptor genes, the targeted deletion of Gabrb3 gene, encoding for the $\beta 3$ subunit, leads to abnormalities in social behavior, cognitive deficits, motor stereotypes, and seizures, reminiscent of the autistic phenotype (DeLorey et al., 1998).

In summary, numerous studies both in human and animal research suggests that GABAergic interneuron development and function are affected in autism. It remains to be seen however, whether these alterations are brain region and/or circuit specific and most importantly, if they are a general feature of all autism cases. So far autism is defined as a "spectrum disorder" due to the extraordinary heterogeneity of intellectual ability, associated symptoms, and possible etiology. Future studies, therefore, are critical to establish specific network alterations that are reliably and consistently associated with the autism phenotype. Moreover, the generation of animal models carrying human mutations will be invaluable in dissecting the network, cellular, and molecular changes underlying autism.

\section{MODULATION OF GABAergic TRANSMISSION AS A TOOL TO RESTORE PLASTICITY}

Multiple lines of evidence critically implicate GABAergic dysfunction in neurodevelopmental diseases, including schizophrenia and autism. It is important to note that alterations in GABAergic functions are most likely not limited to these disorders. For example, a mouse model of neurofibromatosis Type 1, a neurodevelopmental disorder associated with cognitive impairments, including difficulties with visuospatial skills and executive function, as well as an increased incidence of autism, shows increased GABA release, which underlies LTP and learning deficits (Cui et al., 2008). These findings open the question as to whether rescuing specific GABAergic defects might ameliorate at least in part the cognitive deficits. Since the GABAergic network is truly heterogenous with distinct GABAergic cell types, and multiple GABAergic receptor isoforms, further studies are essential to develop a targeted approach toward a specific class of GABAergic cells or/and its associated specific cognitive function(s).

Altered GABA function, caused either by genetic/epigenetic or environmental factors, or most likely by a combination of the above, affects the developmental trajectory of interneuron connectivity (Chattopadhyaya et al., 2007; Baho and Di Cristo, 2012; Wu et al., 2012). In turn, the formation of interneuron connectivity during early development is critical to the emergence of optimal network architecture that subserve different cognitive functions in the adult brain. Therefore it is likely that factors that cause the initial perturbation in GABAergic circuits would consequently affect the processing of incoming sensory stimuli and drive the developmental process along an abnormal trajectory. This leads to important, recurrent questions for the appropriate therapeutic strategies: What is the developmental window of opportunity for pharmacological treatment of neurodevelopmental diseases? Can existing symptoms be corrected or improved, or is it necessary to initiate 
treatment early in pre- or postnatal development prior to the onset of symptoms? In other words, is it possible to change abnormal neuronal circuits after their formation and consolidation? Recent studies aiming at reversing cognitive and neural circuit deficits using genetic, pharmacological, or environmental strategies in different mouse models of neurodevelopmental diseases have shown encouraging results. For example, in a mouse model of Rett syndrome, MeCP2 function was restored during or following onset of symptoms using a tamoxifen-inducible Cre-LoxP strategy, resulting in the robust reversal of several associated phenotypes (Guy et al., 2007). Further, early enriched environment starting before the second postnatal week dramatically improved several phenotypes of MeCP2 mutant mice (Lonetti et al., 2010). In addition, pharmacological treatments have been shown to improve memory impairments in mouse models of Tuberous Sclerosis (Ehninger et al., 2008; Auerbach et al., 2011) or Fragile X Syndrome (Krueger and Bear, 2011). All together, these studies constitute an important proof of principle that the course of neurodevelopmental diseases could be arrested and even reversed with manipulations begun in late childhood and early adolescence, at least in animal models.

Although the human brain retains plasticity through life, continuously reorganizing its connections in the face of new experiences, the foremost period of heightened plasticity is during childhood when there exist "critical periods" during which experience can produce permanent, large-scale changes in neuronal circuits. Understanding the mechanisms that underlie activation and regulation of such critical periods in the central nervous system may help us develop rational pharmacological approaches to correct alterations in the brain of children with neurodevelopmental disorders involving altered synapse formation and/or plasticity.

The most widely studied model of experience-dependent plasticity is ocular dominance (OD) plasticity in the visual cortex. Electrophysiological recordings from neurons in the primary visual cortex show activation to different degrees by visual stimuli presented to one eye or the other, a property termed OD. Closing one eye during a specific postnatal time period causes synaptic reorganization of neural circuits in visual cortex, resulting in lifelong, irreversible reduction of the ability of the deprived eye to drive neuronal responses in the cortex, and an increase in the number of neurons responsive to stimuli presented to the open eye. This time period specific change in eye preference following manipulation of visual inputs is called OD plasticity (Hubel and Wiesel, 1970). In adults, however, such plasticity in OD, while not eliminated, is strongly restricted.

\section{REFERENCES}

Addington, A. M., Gornick, M., Duckworth, J., Sporn, A., Gogtay, N., Bobb, A., Greenstein, D., Lenane, M., Gochman, P., Baker, N., Balkissoon, R., Vakkalanka, R. K., Weinberger, D. R., Rapoport, J. L., and and Straub, R. E. (2005). GAD1 (2q31.1), which encodes glutamic acid decarboxylase (GAD67), is associated with childhood-onset schizophrenia and cortical gray matter volume loss. Mol. Psychiatry 10, 581-588.
Arai, M., Yamada, K., Toyota, T., Obata, N., Haga, S., Yoshida, Y., Nakamura, K., Minabe, Y., Ujike, H., Sora, I., Ikeda, K., Mori, N., Yoshikawa, T., and Itokawa, M. (2006). Association between polymorphisms in the promoter region of the sialyltransferase $8 \mathrm{~B}$ (SIAT8B) gene and schizophrenia. Biol. Psychiatry 59, 652-659.

Auerbach, B. D., Osterweil, E. K., and Bear, M. F. (2011). Mutations causing syndromic autism define an axis

Convergent studies show that development of inhibitory circuitry in the cortex is critical for controlling the onset and time course of critical periods. For example, the onset of visual cortical plasticity is delayed by genetic disruption of GABA synthesis (Hensch et al., 1998). In parallel, application of benzodiazepines or other treatments that accelerate GABA circuit function triggers premature plasticity (Huang et al., 1999; Fagiolini and Hensch, 2000; Di Cristo et al., 2007). Further, recent results implicate intracortical inhibition as a fundamental limiting factor for adult cortical plasticity. In adult animals, where inhibitory circuits are fully developed, a brief reduction of GABAergic inhibition is sufficient to reopen a window of plasticity in the visual cortex well after the normal closure of the critical period (Harauzov et al., 2010). In addition different pharmacological and environmental strategies shown to enhance plasticity in the adult visual cortex, act at least in part, through a reduction of GABAergic inhibition (Sale et al., 2007; Maya-Vetencourt et al., 2008).

In an elegant study, Southwell et al. (2010) showed that transplanted MGE GABAergic precursors are sufficient to trigger a plasticity response in the host cortex of young mice. Interestingly, grafted interneurons promote plasticity only when they reach a cellular age comparable to that of the endogenous counterpart during the critical period, suggesting that plasticity is successfully initiated by a cell-autonomous program present in interneuron progenitors and is minimally influenced by the age of the host tissue. It is still unknown, however, whether transplantation of interneurons could induce visual plasticity in adults; nevertheless these findings suggest that cell transplantation might be effective in triggering plasticity processes.

In addition to GABAergic inhibition, several other factors have been implicated in limiting adult plasticity (Pizzorusso et al., 2002; McGee et al., 2005; Syken et al., 2006; Bavelier et al., 2010; Morishita et al., 2010). Therefore, targeting multiple pathways maybe key to successfully increase plasticity in the adult brain at a level sufficient enough to trigger long-lasting neural circuitry reorganization. Further along the road, coupling cognitive rehabilitation with pharmacological treatments that facilitate brain plasticity, could correct neuronal network connectivity and function and, ultimately, improve cognitive deficits.

\section{ACKNOWLEDGMENTS}

Bidisha Chattopadhyaya is supported by a postdoctoral fellowship from the Savoy Foundation and from the Saint-Justine Hospital Foundation. Graziella Di Cristo is supported by Canada Research Chair Program.

of synaptic pathophysiology. Nature 480, 63-68.

Baddeley, A. (2010). Working memory. Curr. Biol. 20, R136-R140.

Baho, E., and Di Cristo, G. (2012). Synaptic activity is required for the maintenance of GABAergic innervation patterns in the cortex. $\mathrm{J}$. Neurosci. 32, 911-918.

Bailey, A., Le Couteur, A., Gottesman, I., Bolton, P., Siminoff, E., Yuzda, E., and Rutter, M. (1995). Autism as a strongly genetic disorder: evidence from a British twin study. Psychol. Med. 25, 63-77.

Barr, M. S., Farzan, F., Tran, L. C., Chen, R., Fitzgerald, P. B., and Daskalakis, Z. J. (2010). Evidence for excessive frontal evoked gamma oscillatory activity in schizophrenia during working memory. Schizophr. Res. 121, 146-152.

Bartos, M., Vida, I., Frotscher, M., Meyer, A., Monyer, H., Geiger, J. R., and Jonas, P. (2002). Fast synaptic inhibition promotes synchronized 
gamma oscillations in hippocampal interneuron networks. Proc. Natl. Acad. Sci. U.S.A. 99, 13222-13227.

Bartos, M., Vida, I., and Jonas, P. (2007). Synaptic mechanisms of synchronized gamma oscillations in inhibitory interneuron networks. Nat. Rev. Neurosci. 8, 45-56.

Basar-Eroglu, C., Brand, A., Hildebrandt, H., Karolina Kedzior, K., Mathes, B., and Schmiedt, C. (2007). Working memory related gamma oscillations in schizophrenia patients. Int. J. Psychophysiol. 64, 39-45.

Batista-Brito, R., and Fishell, G. (2009). The developmental integration of cortical interneurons into a functional network. Curr. Top. Dev. Biol. 87, 81-118.

Bavelier, D., Levi, D. M., Li, R. W., Dan, Y., and Hensch, T. K. (2010). Removing brakes on adult brain plasticity: from molecular to behavioral interventions. J. Neurosci. 30, 14964-14971.

Belmonte, M. K., Cook, E. H., Anderson, G. M., Rubenstein, J. L., Greenough, W. T., Beckel-Mitchener, A., Courchesne, E., Boulanger, L. M., Powell, S. B., Levitt, P. R., Perry, E. K., Jiang, Y. H., DeLorey, T. M., and and Tierney, E. (2004). Autism as a disorder of neural information processing: directions for research and targets for therapy. Mol. Psychiatry 9, 646-663.

Bertone, A., Mottron, L., Jelenic, P., and Faubert, J. (2003). Motion perception in autism: a "complex" issue. J. Cogn. Neurosci. 15, 218-225.

Boggio, E. M., Lonetti, G., Pizzorusso, T., and Giustetto, M. (2010). Synaptic determinants of rett syndrome. Front. Synaptic. Neurosci. 2:28. doi:10.3389/fnsyn.2010.00028

Cardin, J. A., Carlén, M., Meletis, K., Knoblich, U., Zhang, F., Deisseroth, K., Tsai, L. H., and Moore, C. I. (2009). Driving fast-spiking cells induces gamma rhythm and controls sensory responses. Nature 459, 663-667.

Carlén, M., Meletis, K., Siegle, J. H., Cardin, J. A., Futai, K., VierlingClaassen, D., Rühlmann, C., Jones, S. R., Deisseroth, K., Sheng, M., Moore, C. I., and Tsai, L. H. (2011). A critical role for NMDA receptors in parvalbumin interneurons for gamma rhythm induction and behavior. Mol. Psychiatry 17, 537548.

Casanova, M. F., Buxhoeveden, D., and Gomez, J. (2003). Disruption in the inhibitory architecture of the cell minicolumn: implications for autism. Neuroscientist 9, 496-507.
Chadman, K. K., Gong, S., Scattoni, M. L., Boltuck, S. E., Gandhy, S. U., Heintz, N., and and Crawley, J. N. (2008). Minimal aberrant behavioral phenotypes of neuroligin-3 R451C knockin mice. Autism Res. 1, 147-158.

Chao, H. T., Chen, H., Samaco, R. C., Xue, M., Chahrour, M., Yoo, J., Neul, J. L., Gong, S., Lu, H. C., Heintz, N., Ekker, M., Rubenstein, J. L., Noebels, J. L., Rosenmund, C., and Zoghbi, H. Y. (2010). Dysfunction in GABA signalling mediates autism-like stereotypies and Rett syndrome phenotypes. Nature 468, 263-269.

Chattopadhyaya, B. (2011). Molecular mechanisms underlying activitydependent GABAergic synapse development and plasticity and its implications for neurodevelopmental disorders. Neural Plast. 2011, 734231.

Chattopadhyaya, B., Di Cristo, G., Wu, C. Z., Knott, G., Kuhlman, S., Fu, Y., Palmiter, R. D., and Huang, Z. J. (2007). Regulation of GABAergic axon branching and synaptic innervation by GAD67-mediated GABA synthesis and signaling. Neuron 54, 889-903.

Chattopadhyaya, B., DiCristo, G., Higashiyama, H., Knott, G. W., Kuhlman, S. J., Welker, E., and Huang, Z. J. (2004). Experience and activity-dependent maturation of perisomatic GABAergic innervation in primary visual cortex during a postnatal critical period. J. Neurosci. 24, 9598-9611.

Collins, A. L., Ma, D., Whitehead, P. L., Martin, E. R., Wright, H. H., Abramson, R. K., Hussman, J. P., Haines, J. L., Cuccaro, M. L., Gilbert, J. R., and Pericak-Vance, M. A. (2006). Investigation of autism and GABA receptor subunit genes in multiple ethnic groups. Neurogenetics 7, 167-174.

Craig, A. M., and Kang, Y. (2007). Neurexin-neuroligin signaling in synapse development. Curr. Opin. Neurobiol. 17, 43-52.

Cramer, N. P., Best, T. K., Stoffel, M., Siarey, R. J., and Galdzicki, Z. (2010). GABAB-GIRK2-mediated signaling in Down syndrome. Adv. Pharmacol. 58, 397-426.

Cui, Y., Costa, R. M., Murphy, G. G., Elgersma, Y., Zhu, Y., Gutmann, D. H., Parada, L. F., Mody, I., and Silva, A. J. (2008). Neurofibromin regulation of ERK signaling modulates GABA release and learning. Cell 135, 549-560.

DeLorey, T. M., Handforth, A., and Anagnostaras, S. G. (1998). Mice lacking the $\beta 3$ subunit of the $\operatorname{GABA}(\mathrm{A})$ receptor have the epilepsy phenotype and many of the behavioral characteristics of Angelman syndrome. J. Neurosci. $18,8505-8514$.

Di Cristo, G., Chattopadhyaya, B. Kuhlman, S. J., Fu, Y., Bélanger, M.C., Wu, C. Z., Rutishauser, U., Maffei, L., and Huang, Z. J. (2007) Activity-dependent PSA expression promotes the maturation of GABA inhibition and the onset of critical period plasticity. Nat. Neurosci. 10 1569-1577.

Ehninger, D., Han, S., Shilyansky, C. Zhou, Y., Li, W., Kwiatkowski, D. J., Ramesh, V., and Silva, A. J. (2008). Reversal of learning deficits in a Tsc2+ + mouse model of tuberous sclerosis. Nat. Med. 14, 843-848.

Fagiolini, M., and Hensch, T. K. (2000). Inhibitory threshold for criticalperiod activation in primary visual cortex. Nature 404, 183-186.

Fatemi, S. H., Halt, A. R., Stary, J. M. Kanodia, R., Schulz, S. C., and Realmuto, G. R. (2002). Glutamic acid decarboxylase 65 and $67 \mathrm{kDa}$ proteins are reduced in autistic parietal and cerebellar cortices. Biol. Psychiatry 52, 805-810.

Fatemi, S. H., Reutiman, T. J., Folsom, T. D., Rooney, R. J., Patel, D. H., and Thuras, P. D. (2010). mRNA and protein levels for GABA A $\alpha 4, \alpha 5, \beta 1$ and GABABR1 receptors are altered in brains from subjects with autism. J. Autism Dev. Disord. 40, 743-750.

Fatemi, S. H., Reutiman, T. J., Folsom, T. D., and Thuras, P. D. (2009). GABAA receptor downregulation in brains of subjects with autism. J. Autism Dev. Disord. 39, 223-230.

Fazzari, P., Paternain, A. V., Valiente, M. Pla, R., Luján, R., Lloyd, K., Lerma, J., Marín, O., and Rico, B. (2010). Control of cortical GABA circuitry development by Nrg1 and ErbB4 signalling. Nature 464, 1376-1380.

Gelman, D. M., and Marín, O. (2010). Generation of interneuron diversity in the mouse cerebral cortex. Eur. J. Neurosci. 31, 2136-2141.

Gillberg, C., and Billstedt, E. (2000). Autism and Asperger syndrome: coexistence with other clinical disorders. Acta Psychiatr. Scand. 102, 321-330.

Gogolla, N., Leblanc, J. J., Quast, K. B., Südhof, T. C., Fagiolini, M., and Hensch, T. K. (2009). Common circuit defect of excitatory-inhibitory balance in mouse models of autism. J. Neurodev. Disord. 1, 172-181.

Gonzalez-Burgos, G., Fish, K. N., and Lewis, D. A. (2011). GABA neuron alterations, cortical circuit dysfunction and cognitive deficits in schizophrenia. Neural Plast. 2011, 723184.
Guptill, J. T., Booker, A. B., Gibbs, T. T., Kemper, T. L., Bauman, M. L., and Blatt, G. J. (2007). [3H]-flunitrazepam-labeled benzodiazepine binding sites in the hippocampal formation in autism: a multiple concentration autoradiographic study. J. Autism Dev. Disord. 37, 911-920.

Guy, J., Gan, J., Selfridge, J., Cobb, S., and Bird, A. (2007). Reversal of neurological defects in a mouse model of Rett syndrome. Science 315, 1143-1147.

Haenschel, C., Bittner, R. A., Waltz, J., Haertling, F., Wibral, M., Singer W., Linden, D. E., and Rodriguez, E. (2009). Cortical oscillatory activity is critical for working memory as revealed by deficits in earlyonset schizophrenia. J. Neurosci. 29, 9481-9489.

Haenschel, C., and Linden, D. (2011). Exploring intermediate phenotypes with EEG: working memory dysfunction in schizophrenia. Behav. Brain Res. 216, 481-495.

Harauzov, A., Spolidoro, M., Di Cristo, G., De Pasquale, R., Cancedda, L., Pizzorusso, T., Viegi, A., Berardi, N., and Maffei, L. (2010). Reducing intracortical inhibition in the adult visual cortex promotes ocular dominance plasticity. J. Neurosci. 30, 361-371.

Hasenstaub, A., Shu, Y., Haider, B., Kraushaar, U., Duque, A., and McCormick, A. D. (2005). Inhibitory postsynaptic potentials carry synchronized frequency information in active cortical networks. Neuron 47, 423-435.

Hashimoto, T., Bazmi, H. H., Mirnics, K., Sampson, A. R., and Lewis, D. A. (2008). Conserved regional patterns of GABA-related transcript expression in the neocortex of subjects with schizophrenia. Am. J. Psychiatry 165, 479-489.

Hashimoto, T., Volk, D. W., Eggan, S. M., Mirnics, K., Pierri, J. N., Sun, Z., Sampson, A. R., and Lewis, D. A. (2003). Gene expression deficits in a subclass of GABA neurons in the prefrontal cortex of subjects with schizophrenia. J. Neurosci. 23, 6315-6326.

Hensch, T. K. (2005). Critical period plasticity in local cortical circuits. Nat. Rev. Neurosci. 6, 877-888.

Hensch, T. K., Fagiolini, M., Mataga, N., Stryker, M. P., Baekkeskov, S., and Kash, S. F. (1998). Local GABA circuit control of experiencedependent plasticity in developing visual cortex Science 282, 1504-1508. 
Howard, M. W., Rizzuto, D. S., Caplan, J. B., Madsen, J. R., Lisman, J., Aschenbrenner-Scheibe, R., SchulzeBonhage, A., and Kahana, M. J. (2003). Gamma oscillations correlate with working memory load in humans. Cereb. Cortex 13, 1369-1374.

Huang, Z. J., Di Cristo, G., and Ango, F. (2007). Development of GABA innervation in cerebral and cerebellar cortex. Nat. Rev. Neurosci. 8, 673-686.

Huang, Z. J., Kirkwood, A., Pizzorusso, T., Porciatti, V., Morales, B., Bear, M. F., Maffei, L., and Tonegawa, S. (1999). BDNF regulates the maturation of inhibition and the critical period of plasticity in mouse visual cortex. Cell 98, 739-755.

Huang, Z. J., and Scheiffele, P. (2008). GABA and neuroligin signaling: linking synaptic activity and adhesion in inhibitory synapse development. Curr. Opin. Neurobiol. 18, 77-83.

Hubel, D. H., and Wiesel, T. N. (1970). The period of susceptibility to the physiological effects of unilateral eye closure in kittens. J. Physiol. 206, 419-436.

Isomura, R., Kitajima, K., and Sato, C. (2011). Structural and functional impairments of polysialic acid by a mutated polysialyltransferase found in schizophrenia. J. Biol. Chem. 286, 21535-21545.

Jamain, S., Quach, H., Betancur, C., Råstam, M., Colineaux, C., Gillberg, I. C., Soderstrom, H., Giros, B., Leboyer, M., Gillberg, C., Bourgeron, T., and Paris Autism Research International Sibpair Study. (2003). Mutations of the X-linked genes encoding neuroligins NLGN3 and NLGN4 are associated with autism. Nat. Genet. 34, 27-29.

Jamain, S., Radyushkin, K., Hammerschmidt, K., Granon, S., Boretius, S., Varoqueaux, F., Ramanantsoa, N., Gallego, J., Ronnenberg, A., Winter, D., Frahm, J., Fischer, J., Bourgeron, T., Ehrenreich, H., and Brose, N. (2008). Reduced social interaction and ultrasonic communication in a mouse model of monogenic heritable autism. Proc. Natl. Acad. Sci. U.S.A. 105, 1710-1715.

Kim, H. G., Kishikawa, S., Higgins, A. W., Seong, I. S., Donovan, D. J., Shen, Y., Lally, E., Weiss, L. A., Najm, J., Kutsche, K., Descartes, M., Holt, L., Braddock, S., Troxell, R., Kaplan, L., Volkmar, F., Klin, A., Tsatsanis, K., Harris, D. J., Noens, I., Pauls, D. L., Daly, M. J., MacDonald, M. E., Morton, C. C., Quade, B. J., and Gusella, J. F. (2008). Disruption of neurexin
1 associated with autism spectrum disorder. Am. J. Hum. Genet. 82, 199-207.

Klausberger, T., and Somogyi, P. (2008). Neuronal diversity and temporal dynamics: the unity of hippocampal circuit operations. Science 321, 53-57.

Krueger, D. D., and Bear, M. F. (2011). Toward fulfilling the promise of molecular medicine in fragile X syndrome. Annu. Rev. Med.62, 411-429.

Laumonnier, F., Bonnet-Brilhault, F., Gomot, M., Gomot, M., Blanc, R., David, A., Moizard, M. P., Raynaud, M., Ronce, N., Lemonnier, E., Calvas, P., Laudier, B., Chelly, J., Fryns, J. P., Ropers, H. H., Hamel, B. C., Andres, C., Barthélémy, C., Moraine, C., and Briault, S. (2004). X-linked mental retardation and autism are associated with a mutation in the NLGN4 gene, a member of the neuroligin family. Am. J. Hum. Genet. 74, 552-557.

LeBlanc, J. J., and Fagiolini, M. (2011). Autism: a "critical period" disorder? Neural Plast. 2011, 921680.

Lee, S., Hjerling-Leffler, J., Zagha Fishell, G., and Rudy, B. (2010). The largest group of superficial neocortical GABAergic interneurons expresses ionotropic serotonin receptors. J. Neurosci. 30, 16796-16808.

Levy, S. E., Mandell, D. S., and Schultz, R. T. (2009). Autism. Lancet 374, 1627-1638.

Lewis, D. A. (2011). Pharmacological enhancement of cognition in individuals with schizophrenia. Biol. Psychiatry 69, 397-398.

Lewis, D. A., Hashimoto, T., and Volk, D. W. (2005). Cortical inhibitory neurons and schizophrenia. Nat. Rev. Neurosci. 6, 312-324.

Lonetti, G., Angelucci, A., Morando, L., Boggio, E. M., Giustetto, M., and Pizzorusso, T. (2010). Early environmental enrichment moderates the behavioral and synaptic phenotype of MeCP2 null mice. Biol. Psychiatry 67, 657-665.

Markram, H., Toledo-Rodriguez, M., Wang, Y., Gupta, A., Silberberg, G., and $\mathrm{Wu}, \mathrm{C}$. (2004). Interneurons of the neocortical inhibitory system. Nat. Rev. Neurosci. 5, 793-807.

Maya-Vetencourt, J. F., Sale, A., Viegi, A., Baroncelli, L., De Pasquale, R., O'Leary, O. F., Castrén, E., and Maffei, L. (2008). The antidepressant fluoxetine restores plasticity in the adult visual cortex. Science 320, 385-388.

McGee, A. W., Yang, Y., Fischer, Q. S., Daw, N. W., and Strittmatter, S. M. (2005). Experience-driven plasticity of visual cortex limited by myelin and Nogo receptor. Science 309, 2222-2226.

Minassian, B. A., DeLorey, T. M., Olsen, R. W., Philippart, M., Bronstein, Y., Zhang, Q., Guerrini, R., Van Ness, P. Livet, M. O., and Delgado-Escueta, A. V. (1998). Angelman syndrome: correlations between epilepsy phenotypes and genotypes. Ann. Neurol. 43, 485-493.

Minzenberg, M. J., Firl, A. J., Yoon, J. H., Gomes, G. C., Reinking, C., and Carter, C. S. (2010). Gamma oscillatory power is impaired during cognitive control independent of medication status in first-episode schizophrenia. Neuropsychopharmacology 5, 2590-2599.

Morishita, H., Miwa, J. M., Heintz, N., and Hensch, T. K. (2010). Lynx1, a cholinergic brake, limits plasticity in adult visual cortex. Science 330, 1238-1240.

Oblak, L., Gibbs, T. T., and Blatt, G. J. (2010). Decreased GABA$\mathrm{B}$ receptors in the cingulated cortex and fusiform gyrus in Autism. J. Neurochem. 114, 1414-1423.

Owens, D. F., and Kriegstein, A. R. (2002). Developmental neurotransmitters? Neuron 36, 989-991.

Pizzorusso, T., Medini, P., Berardi, N., Chierzi, S., Fawcett, J. W., and Maffei, L. (2002). Reactivation of ocular dominance plasticity in the adult visual cortex. Science 298 1248-1251.

Pouille, F., and Scanziani, M. (2001). Enforcement of temporal fidelity in pyramidal cells by somatic feedforward inhibition. Science 293, 1159-1163.

Rossignol, E. (2011). Genetics and function of neocortical GABAergic interneurons in neurodevelopmental disorders. Neural Plast. 2011, 649325.

Sale, A., Maya Vetencourt, J. F., Medini, P., Cenni, M. C., Baroncelli, L., De Pasquale, R., and Maffei, L. (2007). Environmental enrichment in adulthood promotes amblyopia recovery through a reduction of intracortical inhibition. Nat. Neurosci. 10, 679-681.

Sernagor, E., Chabrol, F., Bony, G., and Cancedda, L. (2010). GABAergic control of neurite outgrowth and remodeling during development and adult neurogenesis: general rules and differences in diverse systems. Front Cell Neurosci 4:11. doi:10.3389/fncel.2010.00011

Shao, Y., Cuccaro, M. L., Hauser, E. R., Raiford, K. L., Menold, M. M., Wolpert, C. M., Ravan, S. A., Elston, L., Decena, K., Donnelly, S.
L., Abramson, R. K., Wright, H. H., DeLong, G. R., Gilbert, J. R., and Pericak-Vance, M. A. (2003). Fine mapping of autistic disorder to chromosome 15q11-q13 by use of phenotypic subtypes. Am. J. Hum. Genet. 72, 539-548.

Sirota, A., Montgomery, S., Fujisawa, S., Isomura, Y., Zugaro, M., and Buzsáki, G. (2008). Entrainment of neocortical neurons and gamma oscillations by the hippocampal theta rhythm. Neuron 60, 683-697.

Sohal, V. S., Zhang, F., Yizhar, O., and Deisseroth, K. (2009). Parvalbumin neurons and gamma rhythms enhance cortical circuit performance. Nature 459, 698-702.

Somogyi, P., Tamas, G., Lujan, R., and Buhl, E. H. (1998). Salient features of synaptic organisation in the cerebral cortex. Brain Res. Brain Res. Rev. 26, 113-135.

Southwell, D. G., Froemke, R. C., Alvarez-Buylla, A., Stryker, M. P., and Gandhi, S. P. (2010). Cortical plasticity induced by inhibitory neuron transplantation. Science 327, 1145-1148.

Straub, R. E., Lipska, B. K., Egan, M. F., Goldberg, T. E., Callicott, J. H., Mayhew, M. B., Vakkalanka, R. K., Kolachana, B. S., Kleinman, J. E., and Weinberger, D. R. (2007). Allelic variation in GAD1 (GAD67) is associated with schizophrenia and influences cortical function and gene expression. Mol. Psychiatry 12, 854-69.

Südhof, T. C. (2008). Neuroligins and neurexins link synaptic function to cognitive disease. Nature 455, 903-911.

Swadlow, H. A. (2003). Fast-spike interneurons and feedforward inhibition in awake sensory neocortex. Cereb. Cortex 13, 25-32.

Syken, J., Grandpre, T., Kanold, P. O., and Shatz, C. J. (2006). PirB restricts ocular-dominance plasticity in visual cortex. Science 313 , 1795-1800.

Szatmari, P., Paterson, A. D., Zwaigenbaum, L., Roberts, W., Brian, J., Liu, X. Q., Vincent, J. B., Skaug, J. L. Thompson, A. P., Senman, L., Feuk, L., Qian, C., Bryson, S. E., Jones, M. B., Marshall, C. R., Scherer, S. W. Vieland, V. J., Bartlett, C., Mangin, L. V., Goedken, R., Segre, A., PericakVance, M. A., Cuccaro, M. L., Gilbert, J. R., Wright, H. H., Abramson, R. K., Betancur, C., Bourgeron, T., Gillberg, C., Leboyer, M., Buxbaum, J. D., Davis, K. L., Hollander, E., Silverman, J. M., Hallmayer, J., Lotspeich, L., Sutcliffe, J. S., Haines, J. L., 
Folstein, S. E., Piven, J., Wassink, T. H., Sheffield, V., Geschwind, D. H., Bucan, M., Brown, W. T., Cantor, R. M., Constantino, J. N., Gilliam, T. C., Herbert, M., Lajonchere, C., Ledbetter, D. H., Lese-Martin, C., Miller, J., Nelson, S., Samango-Sprouse, C. A., Spence, S., State, M., Tanzi, R. E., Coon, H., Dawson, G., Devlin, B., Estes, A., Flodman, P., Klei, L., McMahon, W. M., Minshew, N., Munson, J., Korvatska, E., Rodier, P. M., Schellenberg, G. D., Smith, M., Spence, M. A., Stodgell, C., Tepper, P. G., Wijsman, E. M., Yu, C. E., Rogé, B., Mantoulan, C., Wittemeyer, K., Poustka, A., Felder, B., Klauck, S. M., Schuster, C., Poustka, F., Bölte, S., Feineis-Matthews, S., Herbrecht, E., Schmötzer, G., Tsiantis, J., Papanikolaou, K., Maestrini, E., Bacchelli, E., Blasi, F., Carone, S., Toma, C., Van Engeland, H., de Jonge, M., Kemner, C., Koop, F., Langemeijer, M., Hijmans, C., Staal, W. G., Baird, G., Bolton, P. F., Rutter, M. L., Weisblatt, E., Green, J., Aldred, C., Wilkinson, J. A., Pickles, A., Le Couteur, A., Berney, T., McConachie, H., Bailey, A. J., Francis, K., Honeyman, G., Hutchinson, A., Parr, J. R., Wallace, S., Monaco, A. P.,
Barnby, G., Kobayashi, K., Lamb, J. A., Sousa, I., Sykes, N., Cook, E. H., Guter, S. J., Leventhal, B. L., Salt, J., Lord, C., Corsello, C., Hus, V., Weeks, D. E., Volkmar, F., Tauber, M., Fombonne, E., Shih, A., Meyer, K. J., and Source Department of Psychiatry and Behavioural Neur. (2007). Mapping autism risk loci using genetic linkage and chromosomal rearrangements. Nat. Genet. 39, 319-28.

Tabuchi, K., Blundell, J., Etherton, M. R., Hammer, R. E., Liu, X., Powell, C. M., and Südhof, T. C. (2007). A neuroligin-3 mutation implicated in autism increases inhibitory synaptic transmission in mice. Science 318, 71-76.

Taniguchi, H., He, M., Wu, P., Kim, S., Paik, R., Sugino, K., Kvitsiani, D., Fu, Y., Lu, J., Lin, Y., Miyoshi, G., Shima, Y., Fishell, G., Nelson, S. B., and Huang, Z. J. (2011). A resource of Cre driver lines for genetic targeting of GABAergic neurons in cerebral cortex. Neuron 71, 995-1013.

Tao, R., Li, C., Zheng, Y., Qin, W., Zhang, J., Li, X., Xu, Y., Shi, Y. Y., Feng, G., and He, L. (2007). Positive association between SIAT8B and schizophrenia in the Chinese Han population. Schizophr. Res. 90, 108-114.

Wen, L., Lu, Y. S., Zhu, X. H., Li, X. M., Woo, R. S., Chen, Y. J., Yin, D. M., Lai, C., Terry, A. V. Jr., Vazdarjanova, A., Xiong, W. C., and Mei, L. (2010). Neuregulin 1 regulates pyramidal neuron activity via ErbB4 in parvalbumin-positive interneurons. Proc. Natl. Acad. Sci. U.S.A. 107, 1211-1216.

Whittington, M. A., Traub, R. D., and Jefferys, J. G. (1995). Synchronized oscillations in interneuron networks driven by metabotropic glutamate receptor activation. Nature 373 612-615.

Wu, X., Fu, Y., Knott, G., Lu, J., Di Cristo, G., and Huang, Z. J. (2012). GABA signaling promotes synapse elimination and axon pruning in developing cortical inhibitory interneurons. J. Neurosci. 32 331-343.

Yasuhara, A. (2010). Correlation between EEG abnormalities and symptoms of autism spectrum disorder (ASD). Brain Dev. 32, 791-798.

Yip, J., Soghomonian, J. J., and Blatt, G. J. (2007). Decreased GAD67
mRNA levels in cerebellar Purkinje cells in autism: pathophysiological implications. Acta Neuropathol. 113, 559-568.

Conflict of Interest Statement: The authors declare that the research was conducted in the absence of any commercial or financial relationships that could be construed as a potential conflict of interest.

Received: 16 December 2011; accepted: 08 May 2012; published online: 31 May 2012.

Citation: Chattopadhyaya $B$ and $D i$ Cristo G (2012) GABAergic circuit dysfunctions in neurodevelopmental disorders. Front. Psychiatry 3:51. doi: 10.3389/fpsyt.2012.00051

This article was submitted to Frontiers in Molecular Psychiatry, a specialty of Frontiers in Psychiatry.

Copyright (๑) 2012 Chattopadhyaya and Di Cristo. This is an open-access article distributed under the terms of the Creative Commons Attribution Non Commercial License, which permits noncommercial use, distribution, and reproduction in other forums, provided the original authors and source are credited. 